\title{
Article
}

\section{Contamination of Heavy Metals, Polychlorinated Dibenzo- $p$-Dioxins/Furans and Dioxin-Like Polychlorinated Biphenyls in Wharf Roach Ligia spp. In Japanese Intertidal and Supratidal Zones}

\author{
Masato Honda ${ }^{1,2}{ }^{\mathbb{D}}$, Xuchun Qiu ${ }^{2}$, Suzanne Lydia Undap ${ }^{2,3}$, Takeshi Kimura ${ }^{4}$, Tsuguhide Hori ${ }^{5}$, \\ Yohei Shimasaki ${ }^{2}$ and Yuji Oshima ${ }^{2, *}$ \\ 1 Botanical Garden, Institute of Nature and Environmental Technology, Kanazawa University, Kakuma, \\ Kanazawa, Ishikawa 920-1192, Japan; mst-honda@se.kanazawa-u.ac.jp \\ 2 Laboratory of Marine Environmental Science, Faculty of Agriculture, Kyushu University, Motooka 744, \\ Ni-shi-ku, Fukuoka 819-0395, Japan; xuchunqiu@ujs.edu.cn (X.Q.); suzanne.undap@gmail.com (S.L.U.); \\ simasaki@agr.kyushu-u.ac.jp (Y.S.) \\ 3 Faculty of Fisheries and Marine Science, Sam Ratulangi University, Jl. Kampus Unsrat Bahu, Kleak, \\ Kota Manado 95115, North Sulawesi, Indonesia \\ 4 ENJEC CO., Ltd., Nagaoka 3-1-18, Minami-ku, Fukuoka 815-0075, Japan; kimura@enjec.com \\ 5 Division of Drug and Food Hygiene, Department of Health Sciences, Fukuoka Institute of Health and \\ Environmental Sciences, Mukaizano 39, Dazaifu, Fukuoka 818-0135, Japan; hori@fihes.pref.fukuoka.jp \\ * Correspondence: yoshima@agr.kyushu-u.ac.jp; Tel.: +81-092-802-4607
}

Citation: Honda, M.; Qiu, X.; Lydia Undap, S.; Kimura, T.; Hori, T.; Shimasaki, Y.; Oshima, Y Contamination of Heavy Metals, Polychlorinated

Dibenzo- $p$-Dioxins/Furans and Dioxin-Like Polychlorinated Biphenyls in Wharf Roach Ligia spp. In Japanese Intertidal and Supratidal Zones. Appl. Sci. 2021, 11, 1856. https://doi.org/10.3390/app11041856

Academic Editor: Franz Jirsa

Received: 21 December 2020

Accepted: 11 February 2021

Published: 20 February 2021

Publisher's Note: MDPI stays neutral with regard to jurisdictional claims in published maps and institutional affiliations.

Copyright: (c) 2021 by the authors. Licensee MDPI, Basel, Switzerland. This article is an open access article distributed under the terms and conditions of the Creative Commons Attribution (CC BY) license (https:/ / creativecommons.org/licenses/by/ $4.0 /)$.
Abstract: We investigated the pollution levels of 6 heavy metals and 29 dioxins (polychlorinated dibenzo- $p$-dioxins (PCDDs), polychlorinated dibenzofurans (PCDFs), and dioxin-like polychlorinated biphenyls (DL-PCBs)) in intertidal and supratidal zones by using wharf roaches (Ligia spp.) collected from 12 sampling sites on the coast of Northeast Japan from November 2011 to June 2012. The total concentrations of heavy metals ranged from 177 to $377 \mu \mathrm{g} / \mathrm{g}$-dry weight (dw), and the predominant metals were copper, zinc, and aluminum. The order of the detected level of heavy metals was zinc $>$ aluminum $>$ copper $>$ cadmium $>$ lead $>$ chromium, and this trend was similar to a previous report. The total toxic equivalent (TEQ) value of the PCDD/Fs ranged from less than the limit of detection (<LOD) to $2.33 \mathrm{pg}-\mathrm{TEQ} / \mathrm{g}-\mathrm{dw}$, and the predominant congener was octachlorodibenzodioxin $(<\mathrm{LOD}$ to $110 \mathrm{pg} / \mathrm{g}-\mathrm{dw})$. Compared with PCDD/Fs, DL-PCBs were detected at a predominantly higher level (total TEQ value: $0.64-27.79 \mathrm{pg}-\mathrm{TEQ} / \mathrm{g}-\mathrm{dw}$ ). Detected levels of dioxins, especially DL-PCBs in the wharf roach, were like those in the bivalves. These results indicate that the wharf roach could reflect heavy metals and dioxin pollution in the supratidal zones and is a suitable environmental indicator for these environmental pollutants. This is the first study to investigate heavy metals, PCDD/Fs, and DL-PCBs pollution in coastal isopods in Japan.

Keywords: supratidal zone; Ligia spp.; heavy metals; polychlorinated dibenzo- $p$-dioxin/furan; dioxin-like polychlorinated biphenyl

\section{Introduction}

The marine environment is highly exposed to natural compounds and anthropogenic products and chemicals that are released daily and/or accidentally [1-3]. Coastal areas, including intertidal/supratidal zones, are highly polluted even though they are important in marine ecosystems and provide reproduction zones for the larval growth of many species. This critical issue is prevalent in many coastal areas globally $[1,4,5]$. A wide variety of pollutants is present, such as pesticides [6], antibiotics [7], polycyclic aromatic hydrocarbons [8], heavy metals, and persistent organic pollutants. These environmental pollutants affect and disrupt marine ecosystems, and biomonitoring is necessary to understand these environmental issues. 
Heavy metal pollution is widespread and is studied traditionally in the field of environmental pollution. Researchers have focused on several highly toxic elements, such as cadmium $(\mathrm{Cd})$, chromium $(\mathrm{Cr})$, mercury, selenium, lead $(\mathrm{Pb})$, arsenic, fluorine, and boron. These toxic heavy metals can be released from natural sources [9-11] and can be discharged from anthropogenic sources, such as industrial activity [12,13]. Mining provides one of the sources of heavy metals of most concern [14,15]. In the 1910s-1970s, wastewater that contained $\mathrm{Cd}$ was released from a mining area in Toyama, Japan, into a surrounding river. The release resulted in a severe health disease, known as "Itai-itai disease", and soil contamination $[16,17]$. Some heavy metals are essential to organisms, but excess amounts cause health issues [18,19]. Heavy metals tend to be detected in aquatic wildlife, fish [20], mussels [21,22], sea mammals [23], and isopods [24-27].

Dioxins, including 75 polychlorinated dibenzo- $p$-dioxins (PCDDs), 135 polychlorinated dibenzofurans (PCDFs), and 12 dioxin-like polychlorinated biphenyls (DL-PCBs), are one of the most known persistent organic pollutant categories that have been regulated by the Stockholm Convention since 2001. These compounds are of great concern as marine wildlife $[28,29]$ and human $[30,31]$ environmental pollutants. These pollutants are ubiquitous marine environmental pollutants globally and have even been detected in polar areas $[32,33]$. The PCDD/F and DL-PCB toxicity depends on each congener chemical structure. The World Health Organization established the "Toxic Equivalency Factor (TEF)", which sets 2,3,7,8-TCDD as the highest toxic dioxin to 1 and converts the toxicity of each dioxin compound as a relative value to assess the total dioxin toxicity (toxic equivalent, TEQ) in 2005. These dioxins are generated as byproducts from the incomplete combustion of substances that contain carbon, oxygen, hydrogen, and chlorine. Due to their high hydrophobicity (water octanol partition coefficient, log Pow: 6.3-8.2), dioxins are highly accumulated in organisms. However, a few studies have reported environmental pollution with these pollutants, especially PCDD/Fs and DL-PCBs, using organisms' habitats in the supratidal zone around Japan.

Environmental surveys of coastal areas tend to focus on intertidal zones and use mussels for biomonitoring $[4,34,35]$. Scientific effort has been expended over several decades to accumulate numerous baseline data. Environmental pollution with many compounds is thought to be distributed in the broad range of coastal areas, including intertidal and supratidal zones [8,36,37]. Environmental research conducted to date has focused mainly on the intertidal zone. One of the most difficult survey points in supratidal zones is the selection of suitable biomonitoring species. To address this scientific gap, our research group used the wharf roach Ligia spp. as an environmental biomonitoring species. Wharf roaches have a global distribution in temperate-tropical areas [38], occur in relatively small habitat areas [39], are omnivorous [40], and may be exposed to environmental pollutants via feeding in land above the tidal line. Previously, we used the wharf roach as an environmental indicator in supratidal zones and investigated the pollution of radiocesium and radio-silver that was released from the Fukushima Daiichi Nuclear Power Plant [36], tributyltin and dibutyltin [37], polycyclic aromatic hydrocarbons (PAHs), and alkylated PAHs [8]. The wharf roach is a promising environmental indicator in supratidal zones and could fill the gap in coastal environmental surveys.

To investigate environmental pollution in coastal areas, especially in supratidal zones, we collected wharf roaches from 12 sampling coastal sites around Central to Northern Japan in 2011-2012 and analyzed heavy metals, PCDD/Fs, and DL-PCBs. We accumulated environmental data on these pollutants in the wharf roach and estimated the ecological risk from these pollutants with regards to their habitat.

\section{Materials and Methods}

2.1. Sampling

Details on wharf roach collection are provided in previous studies [8,36]. Briefly, 12 sampling sites on the central and northern coasts of Japan (Table 1) were selected and wharf roaches were collected manually and/or by using traps from October 2011 to June 
2012. After collection, samples were frozen immediately and kept in storage at $-40{ }^{\circ} \mathrm{C}$. After being frozen, randomly selected samples were placed in a glass beaker and freeze-dried using a FreeZone $2.5 \mathrm{~L}$ benchtop freeze-dry system (Labconco Corp., MO, USA). After freeze-drying, samples were pooled and homogenized for further analysis.

Table 1. Sampling date and location (city, prefecture).

\begin{tabular}{ccc}
\hline Site Number & Sampling Date & Sampling Site (City, Prefecture) \\
\hline 1 & 21 January 2012 & Tateyama, Chiba (TAT) \\
2 & 20 October 2011 & Hachinohe, Aomori (HAC) \\
3 & 19 October 2011 & Usushiri, Hokkaido (USU) \\
4 & 23 October 2011 & Sado, Niigata (SAD) \\
5 & 14 October 2011 & Ishinomaki, Miyagi (ISH) \\
6 & 26 October 2011 & Aomori, Aomori (AOM) \\
7 & 19 October 2011 & Noroshi, Ishikawa (NOR) \\
8 & 19 October 2011 & Noto, Ishikawa (NOT) \\
9 & 27 October 2011 & Gamou, Miyagi (GAM) \\
10 & 27 October 2011 & Sasu, Miyagi (SAS) \\
11 & 27 October 2011 & Onagawa, Miyagi (ONA) \\
12 & 07 June 2012 & Matsukawaura, Fukushima (MAT) \\
\hline
\end{tabular}

\subsection{Heavy Metals Analysis}

An analytical method was followed, "General Rules for Atomic Absorption Spectrochemical Analysis" (JIS K 0121:1993), with slight modification. Briefly, approximately $0.1 \mathrm{~g}$ of dried specimen was weighed and transferred into a Teflon container. The specimen was spiked with $3 \mathrm{~mL}$ of sulfuric acid and $3 \mathrm{~mL}$ of pure water and was decomposed under pressure and at a high temperature. The decomposed specimen was transferred into a $100 \mathrm{~mL}$ Teflon beaker. The decomposition container was rinsed with pure water and the rinse water was added into a specimen beaker. This combined specimen was evaporated to dryness, and a constant volume was obtained by adding $1 \%$ sulfuric acid (v/v). After sample preparation, the heavy metal concentration was analyzed by inductively coupled plasma atomic emission spectroscopy (ICP-AES) (ICPE-9000; Shimadzu, Kyoto, Japan). We analyzed six heavy metals: $\mathrm{Pb}, \mathrm{Cd}, \mathrm{Cr}$, copper $(\mathrm{Cu})$, zinc $(\mathrm{Zn})$, and aluminum ( $\mathrm{Al})$.

\subsection{PCDD/Fs and DL-PCBs Analysis}

The analytical method followed the "Analytical Guideline of Dioxins in Food" with slight modifications. Briefly, after analyzing the total length and body mass of the freezedried specimens, six specimens were mixed and powdered. ${ }^{13} \mathrm{C}$-labeled internal standards (17 congeners of ${ }^{13} \mathrm{C}-2,3,7,8-\mathrm{PCDD} / \mathrm{Fs}, 50 \mathrm{pg}$ each; 12 congeners of ${ }^{13} \mathrm{C}-\mathrm{DL}-\mathrm{PCB}, 200 \mathrm{pg}$ each) were spiked into the weighed specimen. Specimens were extracted using a highspeed solvent-extraction device (ASE-350; Thermo Fisher Scientific, Waltham, MA, USA) with extraction solvent acetone/hexane (1:2) at $150{ }^{\circ} \mathrm{C}$. The extract was concentrated to near dryness by using a rotary evaporator (R-200; BUCHI, Sankt Gallen, Switzerland), and the concentrate was transferred into a weighed clean beaker. After additional drying at $105^{\circ} \mathrm{C}$ for $1 \mathrm{~h}$, the specimen was dissolved with $\sim 10 \mathrm{~mL}$ of hexane, transferred into a $50 \mathrm{~mL}$ glass tube that contained $5 \mathrm{~mL}$ of sulfuric acid, and left overnight. The hexane layer was purified by using a silver nitrate silica gel column and an activated carbon column. A separated layer was loaded onto two connected glass tubes that were filled with silver nitrate silica gel $(0.5 \mathrm{~g})$ and activated carbon $(0.5 \mathrm{~g})$ and eluted with $15 \mathrm{~mL}$ of hexane. The silver nitrate silica gel column was removed and $10 \%$ of dichloromethane in hexane $(\mathrm{v} / \mathrm{v})$ was added to the activated carbon column to elute most PCBs, except the non-ortho PCBs (PCB fraction). Then, $25 \mathrm{~mL}$ of toluene was added to the activated carbon column to elute the PCDDs, PCDFs, and non-ortho PCBs (DXN fraction). The PCB fraction was evaporated to near dryness and reconstituted with $1 \mathrm{~mL}$ of hexane. The reconstituted specimen was purified with a sulfoxide column. After concentration by $\mathrm{N}_{2}$ gas and transferal into a $1.5 \mathrm{~mL}$ gas chromatograph (GC) vial, the specimen was spiked with a 
syringe spike solution $\left({ }^{13} \mathrm{C}-\mathrm{PCB} \# 111,200 \mathrm{pg}\right.$ ) and concentrated to $20 \mu \mathrm{L}$ (mono-ortho PCB sample). The DXN fraction was concentrated and the solvent was changed from toluene to hexane. After concentration by $\mathrm{N}_{2}$ gas and transferal into a $1.5 \mathrm{~mL}$ GC vial, the specimen was spiked with a syringe spike solution $\left({ }^{13} \mathrm{C}\right.$-1,2,3,4-tetrachlorodibenzo-p-dioxin, $\left.50 \mathrm{pg}\right)$ and concentrated to $20 \mu \mathrm{L}$ (DXN sample). Prepared specimens were analyzed by highresolution GC/MS (Agilent 6890 GC; Autospec-Premier MS; Waters, Milford, MA, USA) in selected ion monitoring mode. We analyzed 17 PCDD/Fs (4-8 chlorinated). The PCDDs analyzed were as follows: 2,3,7,8-Tetrachlorodibenzo-p-dioxin (2,3,7,8-TeCDD), 1,2,3,7,8pentachlorodibenzo-p-dioxin (1,2,3,7,8-PeCDD), 1,2,3,4,7,8-hexachlorodibenzo-p-dioxin (1,2,3,4,7,8-HxCDD), 1,2,3,6,7,8-hexachlorodibenzo-p-dioxin (1,2,3,6,7,8-HxCDD), 1,2,3,7,8,9hexachlorodibenzo-p-dioxin (1,2,3,7,8,9-HxCDD), 1,2,3,4,6,7,8-heptachlorodibenzo-p-dioxin $(1,2,3,4,6,7,8-H p C D D)$, and octachlorodibenzo-p-dioxin (OCDD). The PCDFs analyzed were as follows: 2,3,7,8-tetrachlorodibenzofuran (2,3,7,8-TeCDF), 1,2,3,7,8-pentachlorodibenzofuran (1,2,3,7,8-PeCDF), 2,3,4,7,8-pentachlorodibenzofuran (2,3,4,7,8-PeCDF), 1,2,3,4,7,8-hexachlorodibenzofuran (1,2,3,4,7,8-HxCDF), 1,2,3,6,7,8-hexachlorodibenzofuran (1,2,3,6,7,8-HxCDF), 2,3,4,6,7,8-hexachlorodibenzofuran (2,3,4,6,7,8-HxCDF), 1,2,3,7,8,9-hexachlorodibenzofuran (1,2,3,7,8,9-HxCDF), 1,2,3,4,6,7,8-heptachlorodibenzofuran (1,2,3,4,6,7,8-HpCDF), 1,2,3,4,7,8,9heptachlorodibenzofuran $(1,2,3,4,7,8,9-\mathrm{HpCDF})$, and octachlorodibenzofuran (OCDF). Twelve dioxin-like PCBs were analyzed, including non-ortho PCBs 3,4,4',5-tetrachlorobiphenyl

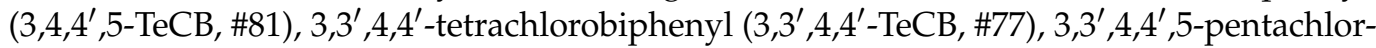
obiphenyl (3,3' $\left., 4,4^{\prime}, 5-\mathrm{PeCB}, \# 126\right)$, and 3, $3^{\prime}, 4,4^{\prime}, 5,5^{\prime}$-hexachlorobiphenyl $\left(3,3^{\prime}, 4,4^{\prime}, 5,5^{\prime}-\mathrm{HxCB}\right.$, \#169); and mono-ortho PCBs 2,3',4,4',5'-pentachlorobiphenyl ( $2^{\prime}, 3,4,4^{\prime}, 5$-pentaCB, \#123), 2,3' $3^{\prime} 4,4^{\prime}, 5$-pentachlorobiphenyl (2,3',4,4',5-pentaCB, \#118), 2,3,4,4', 5-pentachlorobiphenyl

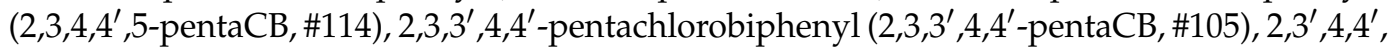
5,5'-hexachlorobiphenyl $\left(2,3^{\prime}, 4,4^{\prime}, 5,5^{\prime}\right.$-hexaCB, \#167), 2,3,3',4,4',5-hexachlorobiphenyl $\left(2,3,3^{\prime}\right.$, 4,4',5-hexaCB, \#156), 2,3,3', 4,4', ,5'-hexachlorobiphenyl $\left(2,3,3^{\prime}, 4,4^{\prime}, 5^{\prime}\right.$-hexaCB, \#157), and

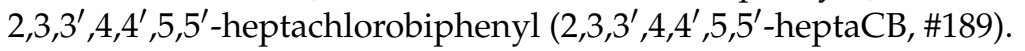

\subsection{Statistical Analysis}

The R software (ver. 4.0.2) was used to conduct the statistical analysis. Statistical significance was set at $p \leq 0.05$. As a nonparametric statistical test, a Spearman's rankorder correlation coefficient was used to examine significant correlations of target analyte concentrations between samples. A Wilcoxon rank sum exact test was used to discern difference among analyte concentrations from each sampling sites. A hierarchical cluster analysis was conducted to estimate grouping patterns, using square Euclidean distances.

\section{Results and Discussion}

\subsection{Heavy Metal Concentrations}

All analyzed samples contained high concentrations of $\mathrm{Cu}, \mathrm{Zn}$, and $\mathrm{Al}$ (Figure 1). The other three metals, $\mathrm{Pb}, \mathrm{Cd}$, and $\mathrm{Cr}$, existed in lower concentrations. $\mathrm{Cu}, \mathrm{Zn}$, and Al had a similar concentration range (33.1-129, 42.6-149, and 13.5-212 $\mu \mathrm{g} / \mathrm{g}$-dry weight $(\mathrm{dw})$, respectively). Al had a broader concentration range with the lowest minimum concentration $(13.5 \mu \mathrm{g} / \mathrm{g}-\mathrm{dw}, \mathrm{AOM})$ and the highest maximum concentration $(212 \mu \mathrm{g} / \mathrm{g}-\mathrm{dw}$, GAM). Compared with $\mathrm{Al}, \mathrm{Cu}$ and $\mathrm{Zn}$ had a relatively constant concentration range. The level of these three heavy metals was similar to previously reported levels in freshwater trichoptera in Japan [41] and the wharf roach in China [27]. Their average Zn concentration $(110 \mu \mathrm{g} / \mathrm{g}-\mathrm{dw})$ was higher than that of $\mathrm{Cu}(75.2 \mu \mathrm{g} / \mathrm{g}-\mathrm{dw})$, and the $\mathrm{Zn}$ concentrations were higher than the $\mathrm{Cu}$ concentration in all samples except for the SAS sample. $\mathrm{Cr}$ had the lowest concentration range $(0.02-0.21 \mu \mathrm{g} / \mathrm{g}-\mathrm{dw})$ among the analyzed metals. The highest $\mathrm{Cr}$ concentration was detected in the USU sample $(0.21 \mu \mathrm{g} / \mathrm{g}-\mathrm{dw})$. Pb was detected at a secondary lower level $(0.22-1.46 \mu \mathrm{g} / \mathrm{g}-\mathrm{dw})$, and the HAC sample had the highest concentration $(1.46 \mu \mathrm{g} / \mathrm{g}-\mathrm{dw})$. Cd was present at a higher concentration than $\mathrm{Zn}$ and $\mathrm{Cr}$ but had a low concentration $(0.46-5.60 \mu \mathrm{g} / \mathrm{g}-\mathrm{dw})$. The NOT samples contained the highest $\mathrm{Cd}$ concentration $(5.60 \mu \mathrm{g} / \mathrm{g}-\mathrm{dw})$. These three metals were detected in a relatively wide 
range; however, their detected levels were lower than those of the other three metals and significant differences in concentrations among the sampling sites were not detected. Ligia italica that was collected in Eastern Sicily, Italy, on September 2001 [26] contained a different pattern of heavy metals with a lower level of $C d(0.22-1.26 \mu \mathrm{g} / \mathrm{g}-\mathrm{dw})$ and a higher level of $\mathrm{Pb}$ and $\mathrm{Cr}$ (1.74-9.30 and 0.18-1.68 $\mu \mathrm{g} / \mathrm{g}$-dw, respectively), compared with this study. These differences probably reflect pollution differences among the sampling sites. The order of the detected level of the heavy metals was $\mathrm{Zn}>\mathrm{Al}>\mathrm{Cu}>\mathrm{Cd}>\mathrm{Pb}>\mathrm{Cr}$, and this trend was similar to a previous report that showed $\mathrm{Cu}>\mathrm{Cd}>\mathrm{Pb}$ in Ligia cinerascens [27] and a previous report on coastal water and sediment [20,42]. The correlations in the three metal couples $(\mathrm{Cu}-\mathrm{Zn}, \mathrm{Cu}-\mathrm{Al}, \mathrm{Zn}-\mathrm{Al})$ were not significant (Spearman's rank correlation test, $p=0.92,0.45,0.69$, respectively). Additionally, the total concentrations of heavy metals were not distributed widely among the 11 sampling sites $(177-377 \mu \mathrm{g} / \mathrm{g}-\mathrm{dw})$. The sum of $\mathrm{Cu}, \mathrm{Zn}$, and $\mathrm{Al}$ was dominant in six metal total concentrations (Figure 2, 97.2\%-99.7\%).

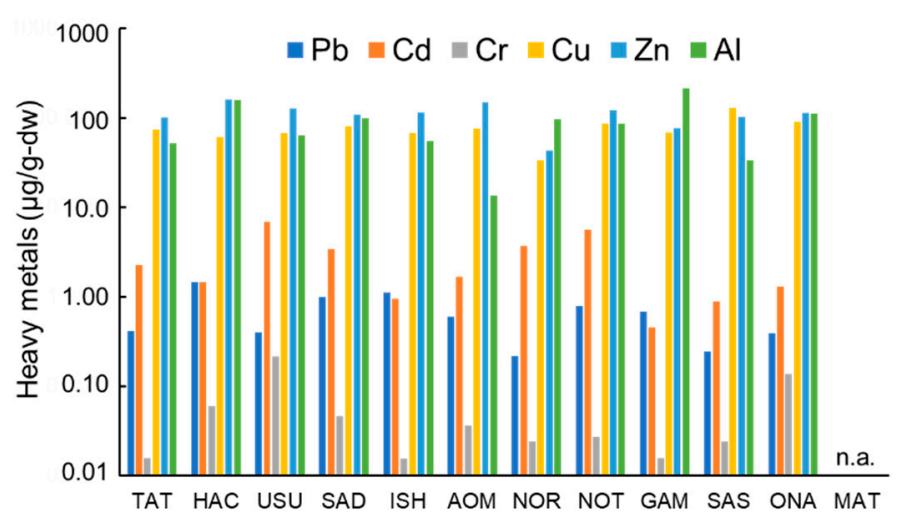

Figure 1. Detected concentration of individual heavy metals in wharf roach $(\mu \mathrm{g} / \mathrm{g}$-dw) collected from 11 sampling sites (n.a.: not available).

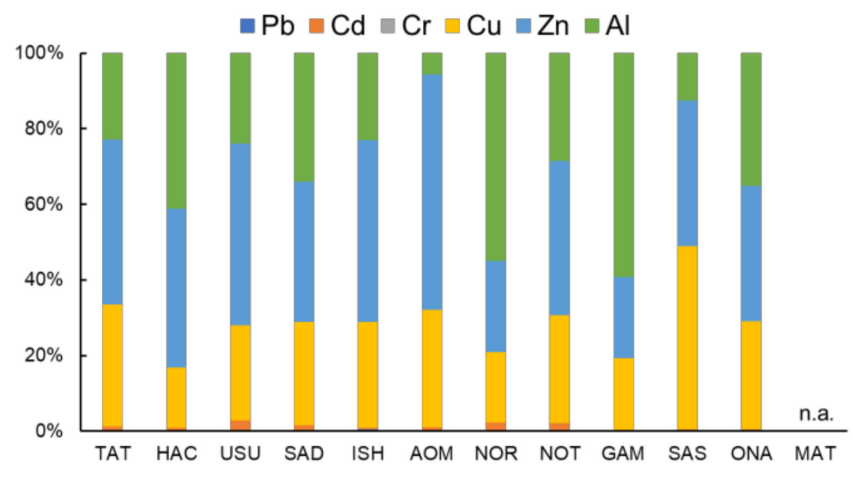

Figure 2. Proportion of each heavy metal concentration in total concentration in 11 sampling sites (n.a.: not available).

\section{2. $P C D D / F$ and $D L-P C B$ Concentrations}

Most PCDDs were not detected except by GAM and MAT (Table 2). Only OCDD was detected in most sampling sites at higher concentrations ( $<\mathrm{LOD}-110 \mathrm{pg} / \mathrm{g}-\mathrm{dw})$. In GAM and MAT's specimens, most PCDDs were detected (6 of 7 and 5 of 7, respectively). Compared with the PCDDs, PCDFs were detected frequently, especially in specimens from HAC, GAM, and MAT (7 of 10, 7 of 10, and 6 of 10, respectively). Twelve DL-PCBs were detected frequently $(83-100 \%)$ at high concentrations ( $<$ LOD-5900 pg/g-dw) among 11 sampling sites. Mono-ortho PCBs had a higher concentration compared with non-ortho PCBs. The trends in the detected level of DL-PCBs among the 11 sampling sites differed slightly from those of the PCDD/Fs. The HAC, GAM, and ONA specimens had relatively 
higher concentrations of DL-PCB congeners (13-4500, 12-5900, and 5.6-1400 pg/g-dw, respectively).

Table 2. Detected concentrations of individual PCDD/Fs and DL-PCBs (pg/g-dw) and total TEQ value (pg-TEQ/g-dw) in wharf roach collected from 11 sampling sites (sample from SAS, Miyagi, was not available).

\begin{tabular}{|c|c|c|c|c|c|c|c|c|}
\hline \multicolumn{3}{|c|}{ Sampling Site } & TAT & HAC & USU & SAD & ISH & AOM \\
\hline \multirow{18}{*}{$\mathrm{PCDD} / \mathrm{Fs}$} & \multirow{7}{*}{ PCDDs } & $2,3,7,8-\mathrm{TeCDD}$ & $<\mathrm{LOD}$ & $<\mathrm{LOD}$ & $<\mathrm{LOD}$ & $<\mathrm{LOD}$ & $<\mathrm{LOD}$ & $<\mathrm{LOD}$ \\
\hline & & 1,2,3,7,8-PeCDD & $<\mathrm{LOD}$ & $<\mathrm{LOD}$ & $<\mathrm{LOD}$ & $<\mathrm{LOD}$ & $<\mathrm{LOD}$ & $<\mathrm{LOD}$ \\
\hline & & 1,2,3,4,7,8-HxCDD & $<\mathrm{LOD}$ & $<\mathrm{LOD}$ & $<\mathrm{LOD}$ & $<\mathrm{LOD}$ & $<\mathrm{LOD}$ & $<\mathrm{LOD}$ \\
\hline & & 1,2,3,6,7,8-HxCDD & $<\mathrm{LOD}$ & $<\mathrm{LOD}$ & $<\mathrm{LOD}$ & $<\mathrm{LOD}$ & $<\mathrm{LOD}$ & $<\mathrm{LOD}$ \\
\hline & & 1,2,3,7,8,9-HxCDD & $<\mathrm{LOD}$ & $<\mathrm{LOD}$ & $<\mathrm{LOD}$ & $<\mathrm{LOD}$ & $<\mathrm{LOD}$ & $<\mathrm{LOD}$ \\
\hline & & $1,2,3,4,6,7,8-\mathrm{HpCDD}$ & $<\mathrm{LOD}$ & $<\mathrm{LOD}$ & $<\mathrm{LOD}$ & 5.8 & $<\mathrm{LOD}$ & $<\mathrm{LOD}$ \\
\hline & & OCDD & $<\mathrm{LOD}$ & 6.9 & 1.5 & 8.0 & 3.7 & 0.66 \\
\hline & \multirow{10}{*}{ PCDFs } & $2,3,7,8-\mathrm{TeCDF}$ & $<\mathrm{LOD}$ & 1.5 & 0.41 & $<\mathrm{LOD}$ & $<\mathrm{LOD}$ & 0.22 \\
\hline & & 1,2,3,7,8-PeCDF & $<\mathrm{LOD}$ & 1.2 & 0.39 & $<\mathrm{LOD}$ & $<\mathrm{LOD}$ & 0.30 \\
\hline & & 2,3,4,7,8-PeCDF & $<\mathrm{LOD}$ & 1.1 & 0.50 & $<\mathrm{LOD}$ & $<\mathrm{LOD}$ & 0.26 \\
\hline & & $1,2,3,4,7,8-\mathrm{HxCDF}$ & $<\mathrm{LOD}$ & 0.79 & $<\mathrm{LOD}$ & $<\mathrm{LOD}$ & $<\mathrm{LOD}$ & $<\mathrm{LOD}$ \\
\hline & & $1,2,3,6,7,8-\mathrm{HxCDF}$ & $<\mathrm{LOD}$ & 0.83 & 0.23 & $<\mathrm{LOD}$ & $<\mathrm{LOD}$ & $<\mathrm{LOD}$ \\
\hline & & $2,3,4,6,7,8-\mathrm{HxCDF}$ & $<\mathrm{LOD}$ & 0.33 & 0.34 & $<\mathrm{LOD}$ & $<\mathrm{LOD}$ & $<\mathrm{LOD}$ \\
\hline & & $1,2,3,7,8,9-\mathrm{HxCDF}$ & $<\mathrm{LOD}$ & $<\mathrm{LOD}$ & $<\mathrm{LOD}$ & $<$ LOD & $<\mathrm{LOD}$ & $<\mathrm{LOD}$ \\
\hline & & 1,2,3,4,6,7,8-HpCDF & $<\mathrm{LOD}$ & 0.55 & $<\mathrm{LOD}$ & $<\mathrm{LOD}$ & $<\mathrm{LOD}$ & $<\mathrm{LOD}$ \\
\hline & & 1,2,3,4,7,8,9-HpCDF & $<\mathrm{LOD}$ & $<\mathrm{LOD}$ & $<\mathrm{LOD}$ & $<\mathrm{LOD}$ & $<\mathrm{LOD}$ & $<\mathrm{LOD}$ \\
\hline & & OCDF & $<\mathrm{LOD}$ & $<\mathrm{LOD}$ & $<\mathrm{LOD}$ & $<\mathrm{LOD}$ & $<\mathrm{LOD}$ & $<\mathrm{LOD}$ \\
\hline & \multicolumn{2}{|c|}{ Dioxins TEQ (pg-TEQ/g-dw) } & $<\mathrm{LOD}$ & 0.72 & 0.26 & 0.06 & 0.00 & 0.11 \\
\hline \multirow{14}{*}{ DL-PCBs } & \multirow{4}{*}{ non-ortho } & $3,4,4^{\prime}, 5-\mathrm{TeCB}(\# 81)$ & $<\mathrm{LOD}$ & 31 & 16 & $<\mathrm{LOD}$ & 11 & 6.0 \\
\hline & & $3,3^{\prime}, 4,4^{\prime}-\mathrm{TeCB}(\# 77)$ & 100 & 730 & 310 & 74 & 250 & 100 \\
\hline & & $3,3^{\prime}, 4,4^{\prime}, 5-\mathrm{PeCB}(\# 126)$ & 18 & 110 & 47 & 14 & 40 & 21 \\
\hline & & $3,3^{\prime}, 4,4^{\prime}, 5,5^{\prime}-\mathrm{HxCB}(\# 169)$ & 3.3 & 13 & 7.7 & $<$ LOD & 5.0 & 3.3 \\
\hline & \multirow{8}{*}{ mono-ortho } & $2^{\prime}, 3,4,4^{\prime}, 5$-pentaCB(\#123) & 7.2 & 55 & 7.9 & 1.7 & 7.1 & 2.4 \\
\hline & & $2,3^{\prime}, 4,4^{\prime}, 5$-pentaCB(\#118) & 310 & 4500 & 740 & 170 & 570 & 260 \\
\hline & & 2,3,4,4',5-pentaCB(\#114) & 7.2 & 120 & 26 & 56 & 17 & 7.2 \\
\hline & & $2,3,3^{\prime}, 4,4^{\prime}$-pentaCB(\#105) & 99 & 2200 & 350 & 64 & 230 & 140 \\
\hline & & $2,3^{\prime}, 4,4^{\prime}, 5,5^{\prime}-$ hexaCB(\#167) & 19 & 360 & 64 & 14 & 36 & 13 \\
\hline & & $2,3,3^{\prime}, 4,4^{\prime}, 5$-hexaCB(\#156) & 36 & 870 & 110 & 24 & 61 & 25 \\
\hline & & $2,3,3^{\prime}, 4,4^{\prime}, 5^{\prime}$-hexaCB(\#157) & 12 & 200 & 25 & 5.8 & 15 & 6.1 \\
\hline & & $2,3,3^{\prime}, 4,4^{\prime}, 5,5^{\prime}$-heptaCB(\#189) & 4.1 & 33 & 15 & 2.0 & 3.8 & 2.6 \\
\hline & \multicolumn{2}{|c|}{ DL-PCBs TEQ (pg-TEQ/g-dw) } & 1.92 & 11.72 & 5.01 & 1.42 & 4.21 & 2.22 \\
\hline & \multicolumn{2}{|c|}{ TOTAL TEQ (pg-TEQ/g-dw) } & 1.92 & 12.44 & 5.27 & 1.48 & 4.21 & 2.33 \\
\hline
\end{tabular}


Table 2. Cont.

\begin{tabular}{|c|c|c|c|c|c|c|c|c|}
\hline \multicolumn{3}{|c|}{ Sampling Site } & NOR & NOT & GAM & SAS & ONA & MAT \\
\hline \multirow{18}{*}{$\mathrm{PCDD} / \mathrm{Fs}$} & \multirow{7}{*}{ PCDDs } & $2,3,7,8-\mathrm{TeCDD}$ & $<\mathrm{LOD}$ & $<\mathrm{LOD}$ & $<\mathrm{LOD}$ & n.a. & $<\mathrm{LOD}$ & $<\mathrm{LOD}$ \\
\hline & & 1,2,3,7,8-PeCDD & $<\mathrm{LOD}$ & $<\mathrm{LOD}$ & 0.81 & n.a. & $<\mathrm{LOD}$ & $<\mathrm{LOD}$ \\
\hline & & 1,2,3,4,7,8-HxCDD & $<\mathrm{LOD}$ & $<\mathrm{LOD}$ & 0.31 & n.a. & $<\mathrm{LOD}$ & 1.3 \\
\hline & & 1,2,3,6,7,8-HxCDD & $<\mathrm{LOD}$ & $<\mathrm{LOD}$ & 1.7 & n.a. & $<\mathrm{LOD}$ & 4.1 \\
\hline & & 1,2,3,7,8,9-HxCDD & $<\mathrm{LOD}$ & $<\mathrm{LOD}$ & 0.75 & n.a. & $<$ LOD & 3.0 \\
\hline & & 1,2,3,4,6,7,8-HpCDD & $<\mathrm{LOD}$ & $<\mathrm{LOD}$ & 5.7 & n.a. & $<\mathrm{LOD}$ & 17 \\
\hline & & OCDD & 3.4 & 110 & 21 & n.a. & 7.6 & 51 \\
\hline & \multirow{10}{*}{ PCDFs } & $2,3,7,8-\mathrm{TeCDF}$ & $<\mathrm{LOD}$ & $<\mathrm{LOD}$ & 1.1 & n.a. & 1.0 & 2.0 \\
\hline & & 1,2,3,7,8-PeCDF & $<\mathrm{LOD}$ & 1.2 & 0.38 & n.a. & 1.5 & 3.8 \\
\hline & & 2,3,4,7,8-PeCDF & $<\mathrm{LOD}$ & 0.87 & 0.73 & n.a. & 1.0 & 1.1 \\
\hline & & $1,2,3,4,7,8-\mathrm{HxCDF}$ & $<\mathrm{LOD}$ & $<\mathrm{LOD}$ & 1.1 & n.a. & $<\mathrm{LOD}$ & 3.1 \\
\hline & & $1,2,3,6,7,8-\mathrm{HxCDF}$ & $<\mathrm{LOD}$ & $<\mathrm{LOD}$ & 1.3 & n.a. & $<\mathrm{LOD}$ & 3.2 \\
\hline & & $2,3,4,6,7,8-\mathrm{HxCDF}$ & $<\mathrm{LOD}$ & $<\mathrm{LOD}$ & 1.1 & n.a. & $<$ LOD & $<\mathrm{LOD}$ \\
\hline & & $1,2,3,7,8,9-\mathrm{HxCDF}$ & $<\mathrm{LOD}$ & $<\mathrm{LOD}$ & $<\mathrm{LOD}$ & n.a. & $<\mathrm{LOD}$ & $<\mathrm{LOD}$ \\
\hline & & $1,2,3,4,6,7,8-\mathrm{HpCDF}$ & $<\mathrm{LOD}$ & $<\mathrm{LOD}$ & 1.6 & n.a. & 1.3 & 3.4 \\
\hline & & 1,2,3,4,7,8,9-HpCDF & $<\mathrm{LOD}$ & $<\mathrm{LOD}$ & $<\mathrm{LOD}$ & n.a. & $<\mathrm{LOD}$ & $<\mathrm{LOD}$ \\
\hline & & OCDF & $<\mathrm{LOD}$ & $<\mathrm{LOD}$ & $<\mathrm{LOD}$ & n.a. & $<\mathrm{LOD}$ & $<\mathrm{LOD}$ \\
\hline & \multicolumn{2}{|c|}{ Dioxins TEQ (pg-TEQ/g-dw) } & 0.00 & 0.33 & 1.86 & n.a. & 0.46 & 2.33 \\
\hline \multirow{14}{*}{ DL-PCBs } & \multirow{4}{*}{ non-ortho } & $3,4,4^{\prime}, 5-\mathrm{TeCB}(\# 81)$ & 5.3 & 4.9 & 48 & n.a. & 19 & 9.3 \\
\hline & & $3,3^{\prime}, 4,4^{\prime}-\mathrm{TeCB}(\# 77)$ & 94 & 55 & 1100 & n.a. & 340 & 100 \\
\hline & & $3,3^{\prime}, 4,4^{\prime}, 5-\mathrm{PeCB}(\# 126)$ & 19 & 5.3 & 270 & n.a. & 51 & 40 \\
\hline & & $3,3^{\prime}, 4,4^{\prime}, 5,5^{\prime}-\mathrm{HxCB}(\# 169)$ & 1.3 & 3.1 & 12 & n.a. & 5.6 & 9.9 \\
\hline & \multirow{8}{*}{ mono-ortho } & $2^{\prime}, 3,4,4^{\prime}, 5$-pentaCB(\#123) & 4.1 & 2.0 & 55 & n.a. & 15 & 12 \\
\hline & & $2,3^{\prime}, 4,4^{\prime}, 5$-pentaCB(\#118) & 220 & 97 & 5900 & n.a. & 1400 & 660 \\
\hline & & 2,3,4,4',5-pentaCB(\#114) & 6.7 & 3.5 & 130 & n.a. & 42 & 20 \\
\hline & & $2,3,3^{\prime}, 4,4^{\prime}$-pentaCB(\#105) & 100 & 46 & 2100 & n.a. & 390 & 270 \\
\hline & & $2,3^{\prime}, 4,4^{\prime}, 5,5^{\prime}$-hexaCB(\#167) & 11 & 9.2 & 510 & n.a. & 96 & 54 \\
\hline & & $2,3,3^{\prime}, 4,4^{\prime}, 5$-hexaCB(\#156) & 18 & 13 & 1100 & n.a. & 160 & 110 \\
\hline & & $2,3,3^{\prime}, 4,4^{\prime}, 5^{\prime}$-hexaCB(\#157) & 6.8 & 3.4 & 200 & n.a. & 30 & 24 \\
\hline & & $2,3,3^{\prime}, 4,4^{\prime}, 5,5^{\prime}$-heptaCB(\#189) & $<\mathrm{LOD}$ & 3.0 & 34 & n.a. & 7.4 & 8.4 \\
\hline & \multicolumn{2}{|c|}{ DL-PCBs TEQ (pg-TEQ/g-dw) } & 1.96 & 0.64 & 27.79 & n.a. & 5.37 & 4.34 \\
\hline & \multicolumn{2}{|c|}{ TOTAL TEQ (pg-TEQ/g-dw) } & 1.96 & 0.97 & 29.64 & n.a. & 5.83 & 6.68 \\
\hline
\end{tabular}

The PCDD/F congener composition differed among the 11 sampling sites. The highestconcentration congener was OCDD in all sampling sites, and this trend was more noticeable in the work by ISH, NOR, and NOT $(100 \%, 100 \%$, and $98 \%$, respectively, Figure 3, Table S1: supplementary materials). In other sites, the OCDD burden was similar (44.6\%-61.3\%). However, other congeners were different. The SAD sample contained a high percentage of 1,2,3,4,6,7,8-HpCDD (42\%), which was different from the other sites. In other sites, the low-chlorinated PCDF concentrations were higher than other congeners, but no other constant trend was observed. These results may reflect a site-specific contamination source. 


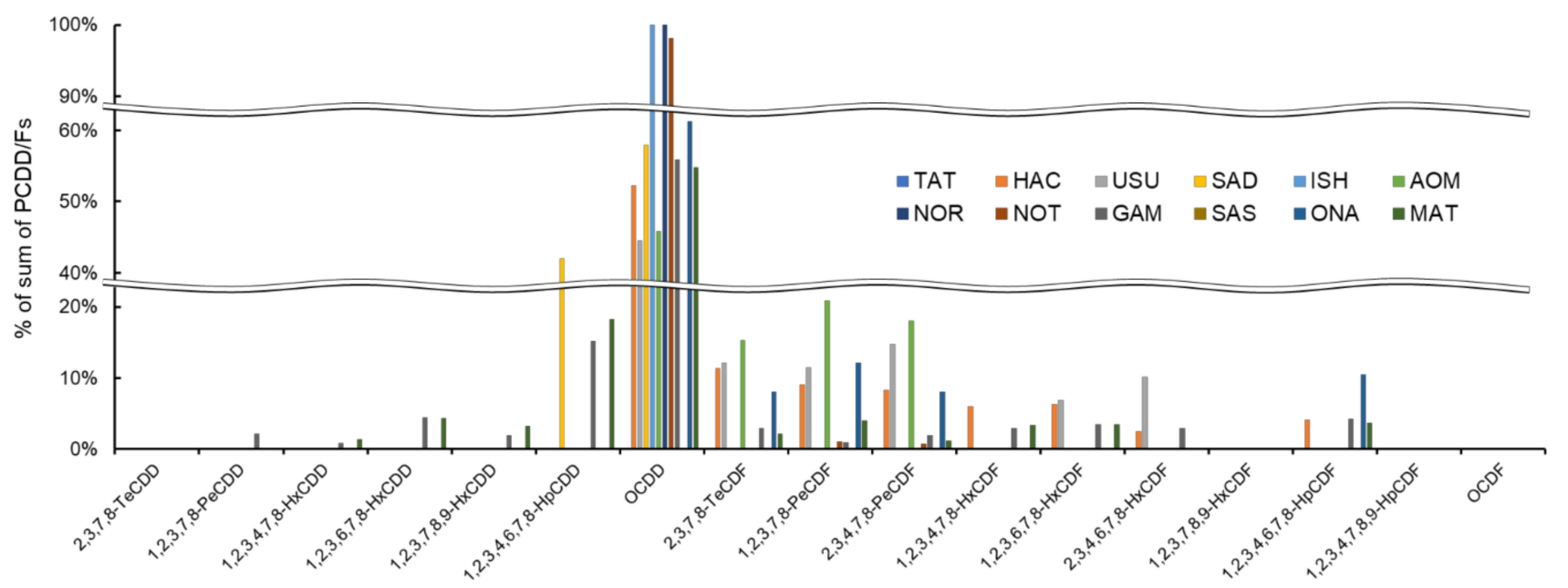

Figure 3. Percentage of individual PCDD/Fs for sum of PCDD/Fs at 11 sampling sites.

Compared with the PCDD/Fs, the DL-PCBs had almost the same congener pattern among the 11 sampling sites. The most dominant congener was 2,3',4,4',5-pentaCB (\#118: 39.5\%-54.8\%) after 2,3,3',4,4'-pentaCB (\#105: 15.0\%-23.9\%) (Figure 4, Table S2). This trend indicated that the contamination source of DL-PCBs was almost similar among the 11 sampling sites. This congener concentration composition was similar to that of mussels in previous studies $[28,43,44]$. However, $3,3^{\prime}, 4,4^{\prime}-\mathrm{TeCB}$ (\#77: 7.6\%-22.4\%) existed in a relatively higher percentage compared with the previous research. In the study by Ohashi [28], a higher concentration of $3,3^{\prime}, 4,4^{\prime}-\mathrm{TeCB}$ (\#77) was observed from sediment compared with the analyzed fishes. The wharf roach lived on a supratidal zone (terrestrial field); therefore, the exposure pathway may be different from the marine organisms. Exposure via soil has a higher importance with regards to $3,3^{\prime}, 4,4^{\prime}-\mathrm{TeCB}$ (\#77) pollution in terrestrial organisms compared with marine organisms. This constant trend was not correlated with the log $\mathrm{P}_{\mathrm{ow}}$ value of each DL-PCBs among the 11 sampling sites (Spearman's rank correlation, $p=0.215-0.675)$.

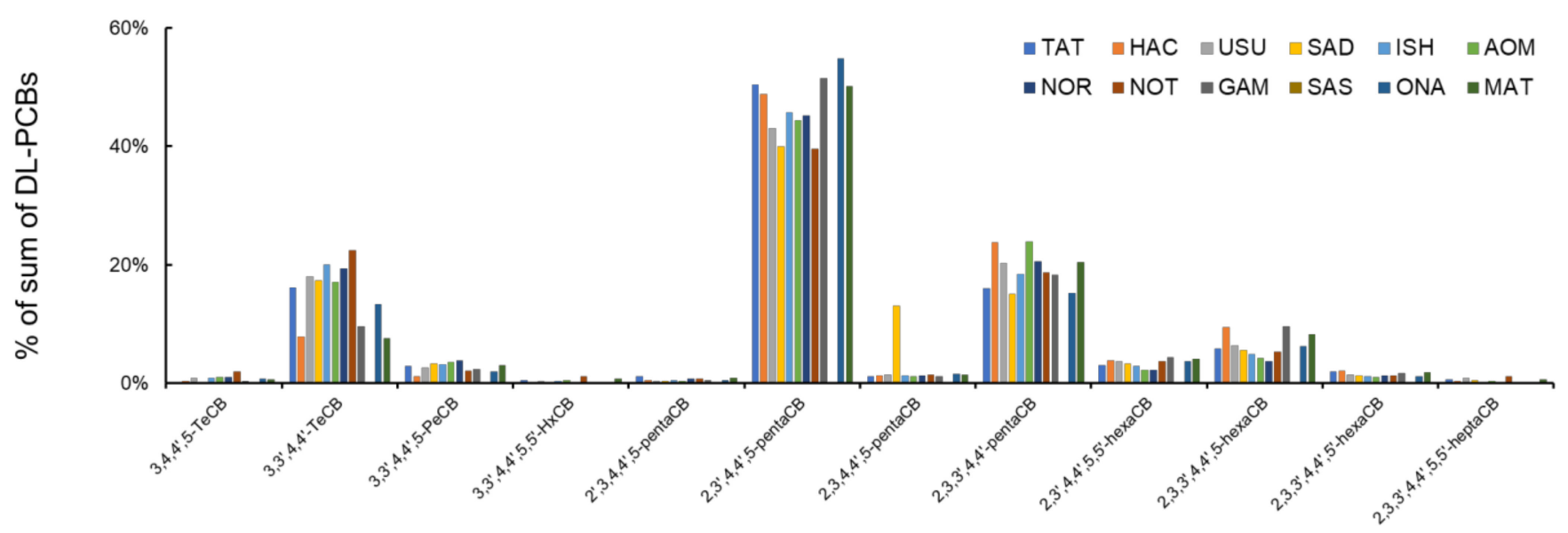

Figure 4. Percentage of individual DL-PCBs in the sum of DL-PCBs at 11 sampling sites.

\subsection{Hierarchical Cluster Analysis}

The hierarchical cluster analysis showed different clustering depending on whether they were calculated using heavy metals or dioxins (Figure 5a,b). However, in both cases, HAC and GAM were separated from other sampling sites. In the case of heavy metal concentrations, HAC and GAM were separated from the other nine sites. However, linkage 
heights between the two sites is high (100). The NOR sample was also separated from the other sites. The separation of these three sites from other sites was induced by high relative concentrations of Al. The other eight sites were more closely clustered. In particular, there are two small clusters: NOT, SAD, and ONA; and TAT, USU, and ISH. The clustering with dioxins (Figure $5 b$ ) also indicate that HAC and GAM were different from the other nine sites. These differences were likely the result of significantly higher concentrations of DL-PCBs (total DL-PCBs: 9222 and 11459 pg/g-dw, respectively). The ONA sample was secondly separated from other eight sites, and completely far from HAC and GAM. Compared with the results of heavy metals, the other eight sites were more clustered, forming two groups: NOT, SAD, TAT, AOM, and NOR; and USU, ISH, and MAT. The different grouping patterns that emerge when the analyses are performed with heavy metals and dioxins suggest differing contaminant sources, accumulation patterns, and mobilities in water. This is particularly the case with the HAC and GAM sites.

(a)

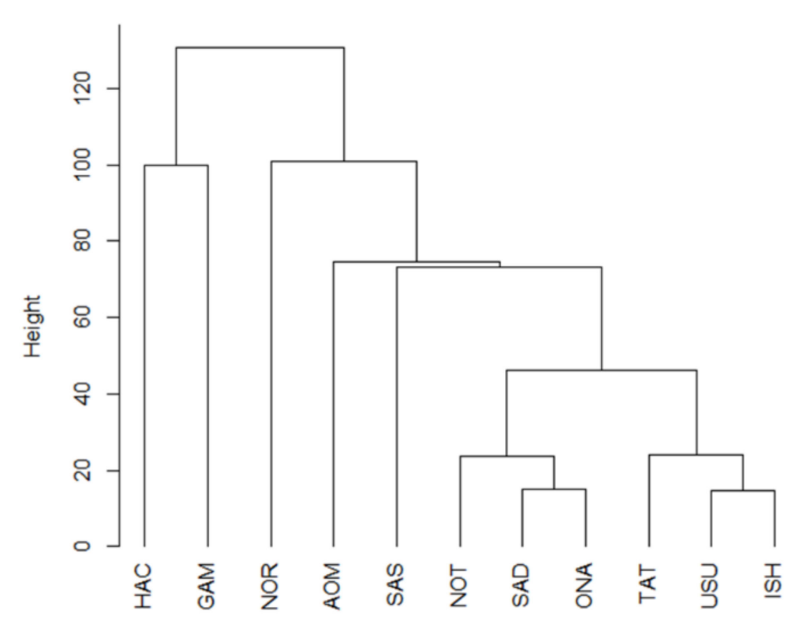

(b)

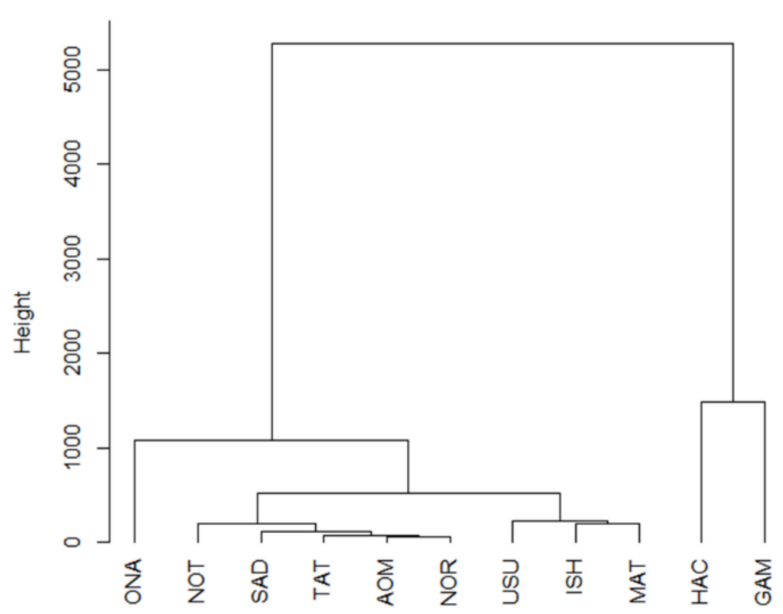

Figure 5. Hierarchical dendrogram for 11 sampling sites obtained using hierarchical cluster analysis with an average linkage method: (a) calculated using heavy metal concentrations and (b) calculated using PCDD/F and DL-PCB concentrations.

\subsection{Ecotoxicological Risk for Wharf Roach}

Normally, heavy metal and PCDD/F toxicities depend on the species. However, significant concentrations of heavy metals and PCDD/F were detected in wharf roach, which suggest a risk of PCDD/F toxicity to this isopod.

$\mathrm{Pb}, \mathrm{Cd}$, and $\mathrm{Cr}$ (particularly hexavalent chromium) have a high toxicity. However, due to arthropod exoskeleton molting, isopods can reduce the risk from excessive heavy metal contamination [45]. In this study, the concentrations of these three heavy metals were lower compared with the other heavy metals. In particular, $\mathrm{Cr}$ was detected at low concentrations $(0.02-0.21 \mu \mathrm{g} / \mathrm{g}-\mathrm{dw})$, which is comparable to a previous study that showed $0.18-1.68 \mu \mathrm{g} / \mathrm{g}-\mathrm{dw}$ in L. italica [26]. However, the detected concentrations of $\mathrm{Cu}, \mathrm{Cd}$, and $\mathrm{Pb}(33.1-129,0.46-6.85$, and $0.22-1.46 \mu \mathrm{g} / \mathrm{g}-\mathrm{dw}$, respectively) are slightly higher than reported in L. cinerascens (23.1-35.6, 0.319-0.893, and 0.0220-0.218 $\mu \mathrm{g} / \mathrm{g}$-wet, respectively) from China [27]. Prato et al. [46] reported that the $96 \mathrm{~h}-\mathrm{LC} 50$ of $\mathrm{Cu}$ and Cd on Sphaeroma serratum (marine isopod) was $4.60 \mathrm{mg} / \mathrm{L}$ and $4.79 \mathrm{mg} / \mathrm{L}$, and on Idotea baltica (marine isopod) it was $1.45 \mathrm{mg} / \mathrm{L}$ and $1.29 \mathrm{mg} / \mathrm{L}$. Hong and Reish [47] reported that the $96 \mathrm{~h}-\mathrm{LC} 50$ in sea water on Jaeropsis sp. and Limnoria tripunctata (both marine isopods) was 0.41 and $7.12 \mathrm{mg} / \mathrm{L}$. These heavy metal concentrations in sea water were in almost the same range as those in wharf roach in this study. These heavy metals can accumulate in crustacean bodies from environmental media [48,49], having high bioconcentration factors (BCFs): $\mathrm{Cd}$ 17000, $\mathrm{Pb}$ 31000, Cu 120000, and Zn 9200 for freshwater isopod Asellus aquaticus (L.) [50]; 
and Cu 2060 and Cd 311 for marine amphipod Paramorea walkeri [51]. Even though the sensitivity to heavy metals differs among isopod species, the contamination level of heavy metals in this study poses an ecological risk to the wharf roach.

The total TEQs of the PCDD/Fs and DL-PCBs in the total dried body weight were discussed to assess the ecological risk (Table 2). MAT's sample had the highest PCDD/Fs (2.33 pg-TEQ/g-dw), followed by GAM's sample (1.86 pg-TEQ/g-dw). Compared with these two sampling sites, the other site had a lower PCDD/Fs level $(<\mathrm{LOD}-0.72 \mathrm{pg}-\mathrm{TEQ} / \mathrm{g}-$ $\mathrm{dw})$. DL-PCBs were detected at a higher level (0.64-27.79 pg-TEQ/g-dw) compared with the PCDD/Fs. The GAM sample contained the highest amount of DL-PCBs (27.79 pgTEQ/g-dw), followed by HAC's sample (11.72 pg-TEQ/g-dw). Other samples contained slightly lower levels $(0.64-5.37 \mathrm{pg}-\mathrm{TEQ} / \mathrm{g}-\mathrm{dw})$. The total TEQs of the PCDD/Fs and those of DL-PCBs in the total dried body weight were correlated significantly (Spearman's rank correlation test, $p=0.04$ ), and this correlation trend was retained in the total TEQ value in the lipid $(p=0.03)$. The TEQ of the DL-PCBs was dominant in the total TEQ $(65 \%-100 \%$, Figure 6). However, the contribution ratios of the PCDD/Fs in the total TEQ in NOT and MAT were higher than in the other nine sampling sites ( $34 \%$ and $35 \%$, respectively). These detected levels of dioxins were higher than those detected previously in mussels $[43,52]$ and small marine arthropods [53]. However, currently detected levels in the wharf roach were similar and/or lower than in marine crabs [54-56]. These differences may be caused by trophic level, species differences on feeding habitat, and metabolism. Due to a lack of toxicological information, it is difficult to estimate the ecotoxicological risk of dioxins on the wharf roach. Michletti et al. [56] detected a relatively higher level of dioxins on crab Carcinus mediterraneus and estimated a significant risk from dioxins. The ecological risk of dioxins on the wharf roach remains unclear, however, and should be studied further.

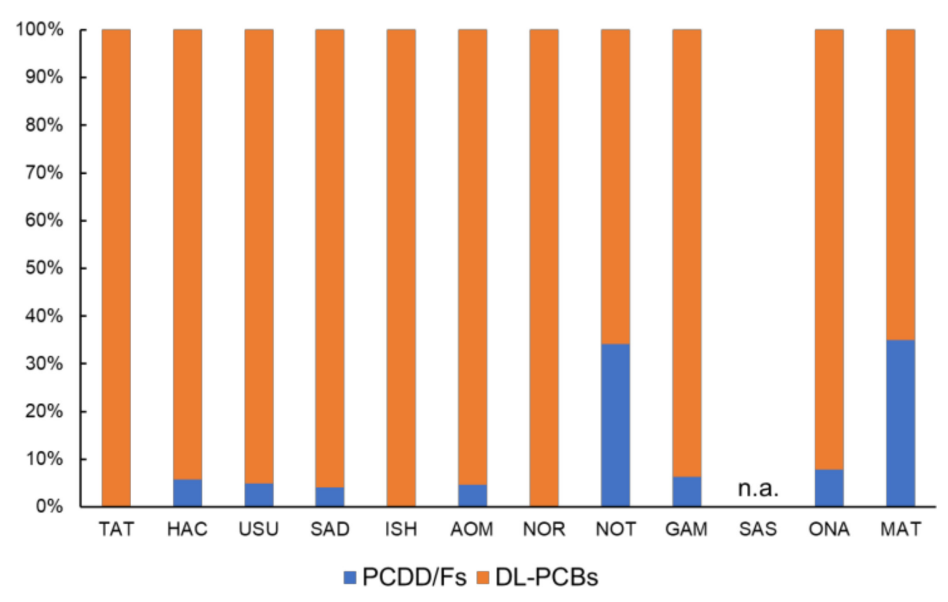

Figure 6. Proportion of PCDD/Fs and DL-PCBs on total TEQ at 11 sampling sites.

\subsection{Case Study: Effect of the Great East Japan Earthquake}

Enormous amounts of debris and anthropogenically derived chemicals were released from damaged areas to surrounding coastal areas by the tsunami that followed the Great East Japan Earthquake [57-59]. Related areas were exposed to heavy metals and dioxins. For this reason, we expected that the damaged areas site 2 (HAC), 5 (ISH), 9 (GAM), 10 (SAS), 11 (ONA), and 12 (MAT) had high concentrations of these pollutants. However, no significant difference in total concentration of heavy metals was observed between the damaged areas and others (177-299 $\mu \mathrm{g} / \mathrm{g}-\mathrm{dw}$ and 241-377 $\mu \mathrm{g} / \mathrm{g}-\mathrm{dw}$ ) (Wilcoxon rank sum exact test: $p=0.08$ ). Heavy metal pollution in these areas occurred immediately after the earthquake and tsunami, but this was not a serious problem [60]. The total TEQs of the dioxins in the damaged areas were significantly higher than others (4.21-29.64 pg-TEQ/g$\mathrm{dw}$ and $0.97-5.27 \mathrm{pg}-\mathrm{TEQ} / \mathrm{g}-\mathrm{dw}$ ) (Wilcoxon rank sum exact test: $p<0.01$ ). Wharf roaches from GAM and HAC contained higher levels of dioxins (29.64 and 12.44 pg-g/g-dry, respectively). Ishiyama et al. [61] reported a significant elevation of PCB concentration in 
blue mussel Mytilus galloprovincialis from the Miyagi prefecture after the tsunami (collection date: June 2011). Additionally, marine sediment around sampling sites contained a higher level of dioxins compared with the surrounding sea area [62]. Current results showed a relatively higher level of dioxin pollution in these areas; therefore, one pollution exposure factor was the earthquake and ensuing tsunami.

A highly polluted area was not included as a sampling site in this study. Therefore, in the future, the wharf roach should be used as an environmental indicator of multi-class pollution for polluted areas, such as developed ports, discharge ports of industrial waste, and sewage treatment plants.

\section{Conclusions}

This study presented new data on the level of heavy metals, PCDD/Fs, and DL-PCBs in the wharf roach. The predominant heavy metals were $\mathrm{Cu}, \mathrm{Zn}$, and $\mathrm{Al}$. The detected concentrations of PCDDs were higher than those of the PCDFs. Among the PCDD/Fs, the predominant congener was OCDD. Compared with the PCDD/Fs, the DL-PCBs were detected with higher concentrations. The detected levels of dioxins, especially DL-PCBs, in the wharf roach were similar to those in bivalves. These results indicate that wharf roach could reflect heavy metal and dioxin pollution in the supratidal zones and is a suitable environmental indicator for these environmental pollutants. To our knowledge, this is the first study to investigate dioxin pollution in coastal isopods and to report pollution of heavy metals and dioxins in supratidal zones around Japan. However, the contamination source, pathway, and ecological risk of these pollutants on the wharf roach and related coastal habitats remains unclear. Thus, further study is required.

Supplementary Materials: The following are available online at https:/ / www.mdpi.com/2076-341 7/11/4/1856/s1, Table S1: Percentage of individual PCDD/Fs for sum of PCDD/Fs at 11 sampling sites, Table S2: Percentage of individual DL-PCBs in the sum of DL-PCBs at 11 sampling sites.

Author Contributions: Conceptualization, M.H. and Y.O.; methodology, X.Q., S.L.U., T.K. and T.H.; formal analysis, M.H. and T.H.; investigation, M.H., X.Q., S.L.U., T.K. and T.H.; resources, Y.O.; writing-original draft preparation, M.H.; writing—review and editing, Y.S. and Y.O.; supervision, Y.O.; project administration, Y.O.; funding acquisition, Y.O. All authors have read and agreed to the published version of the manuscript.

Funding: This research was funded by the JKA Foundation and by the cooperative research program of the Institute of Nature and Environmental Technology, Kanazawa University, Acceptance No. 5, 2015.

Institutional Review Board Statement: Experiments were conducted in accordance with the Japanese Ministry of Education, Culture, Sports, Science and Technology, and Kyushu University and Kanazawa University guidelines for the protection of animal welfare.

Informed Consent Statement: Not applicable.

Data Availability Statement: Not applicable.

Acknowledgments: We thank Laura Kuhar, from Edanz Group (https: / / en-author-services.edanzgroup. $\mathrm{com} /$ ) for editing a draft of this manuscript.

Conflicts of Interest: The authors declare no conflict of interest.

\section{References}

1. Bejarano, A.C.; Michel, J. Oil spills and their impacts on sand beach invertebrate communities: A literature review. Environ. Pollut. 2016, 218, 709-722. [CrossRef]

2. Koyama, J.; Uno, S.; Nagai, Y.; Anukorn, B. Early monitoring of spilled oil contamination in Rayong, Thailand. Jpn. J. Environ. Toxicol. 2016, 19, 25-33. [CrossRef]

3. Uno, S.; Koyama, J.; Kokushi, E.; Monteclaro, H.; Santander, S.; Cheikyula, J.O.; Miki, S.; Añasco, N.; Pahila, I.G.; Taberna, H.S., Jr.; et al. Monitoring of PAHs and alkylated PAHs in aquatic organisms after 1 month from the Solar I oil spill off the coast of Guimaras Island, Philippines. Environ. Monit. Assess. 2010, 165, 501-515. [CrossRef] 
4. Azizi, G.; Akodad, M.; Baghour, M.; Layachi, M.; Moumen, A. The use of Mytilus spp. mussels as bioindicators of heavy metal pollution in the coastal environment. A review. J. Mater. Environ. Sci. 2018, 9, 1170-1181. [CrossRef]

5. Zhang, Z.W.; Xu, X.R.; Sun, Y.X.; Yu, S.; Chen, Y.S.; Peng, J.X. Heavy metal and organic contaminants in mangrove ecosystems of China: A review. Environ. Sci. Pollut. Res. 2014, 21, 11938-11950. [CrossRef] [PubMed]

6. Hano, T.; Ito, K.; Ohkubo, N.; Sakaji, H.; Watanabe, A.; Takashima, K.; Sato, T.; Sugaya, T.; Matsuki, K.; Onduka, T.; et al. Occurrence of neonicotinoids and fipronil in estuaries and their potential risks to aquatic invertebrates. Environ. Pollut. 2019, 252, 205-215. [CrossRef]

7. Xue, X.; Xue, J.; Liu, W.; Adams, D.H.; Kannan, K. Trophic magnification of parabens and their metabolites in a subtropical marine food web. Environ. Sci. Technol. 2017, 51, 780-789. [CrossRef]

8. Honda, M.; Qiu, X.; Koyama, J.; Uno, S.; Undap, S.L.; Shimasaki, Y.; Oshima, Y. The wharf roach, Ligia sp., A novel indicator of polycyclic aromatic hydrocarbon contamination in coastal areas. Int. J. Environ. Res. 2018, 12, 1-11. [CrossRef]

9. Ansari, T.M.; Marr, I.L.; Tariq, N. Heavy metals in marine pollution perspective-a mini review. J. Appl. Sci. 2004, 4, 1-20. [CrossRef]

10. Chanpiwat, P.; Lee, B.T.; Kim, K.W.; Sthiannopkao, S. Human health risk assessment for ingestion exposure to groundwater contaminated by naturally occurring mixtures of toxic heavy metals in the Lao PDR. Environ. Monit. Assess. 2014, 186, 4905-4923. [CrossRef]

11. Mohammed, A.S.; Kapri, A.; Goel, R. Heavy metal pollution: Source, impact, and remedies. In Biomanagement of MetalContaminated Soils; Khan, M.S., Zaidi, A., Goel, R., Musarrat, J., Eds.; Springer Netherlands: Dordrecht, The Netherlands, 2011; Volume 20, pp. 1-28.

12. Naser, H.A. Assessment and management of heavy metal pollution in the marine environment of the Arabian Gulf: A review. Mar. Pollut. Bull. 2013, 72, 6-13. [CrossRef] [PubMed]

13. Pen-Mouratov, S.; Shukurov, N.; Steinberger, Y. Influence of industrial heavy metal pollution on soil free-living nematode population. Environ. Pollut. 2008, 152, 172-183. [CrossRef]

14. Mishra, V.K.; Upadhyaya, A.R.; Pandey, S.K.; Tripathi, B.D. Heavy metal pollution induced due to coal mining effluent on surrounding aquatic ecosystem and its management through naturally occurring aquatic macrophytes. Bioresour. Technol. 2008, 99, 930-936. [CrossRef]

15. Ning, L.; Liyuan, Y.; Jirui, D.; Xugui, P. Heavy metal pollution in surface water of Linglong gold mining area, China. Procedia Environ. Sci. 2011, 10, 914-917. [CrossRef]

16. Horiguchi, H.; Teranishi, H.; Niiya, K.; Aoshima, K.; Katoh, T.; Sakuragawa, N.; Kasuya, M. Hypoproduction of erythropoietin contributes to anemia in chronic cadmium intoxication: Clinical study on Itai-itai disease in Japan. Arch. Toxicol. 1994, 68, 632-636. [CrossRef]

17. Inaba, T.; Kobayashi, E.; Suwazono, Y.; Uetani, M.; Oishi, M.; Nakagawa, H.; Nogawa, K. Estimation of cumulative cadmium intake causing Itai-itai disease. Toxicol. Lett. 2005, 159, 192-201. [CrossRef]

18. Ali, H.; Khan, E. Trophic transfer, bioaccumulation, and biomagnification of non-essential hazardous heavy metals and metalloids in food chains/webs-Concepts and implications for wildlife and human health. Hum. Ecol. Risk Asses. 2019, 25, 1353-1376. [CrossRef]

19. Gall, J.E.; Boyd, R.S.; Rajakaruna, N. Transfer of heavy metals through terrestrial food webs: A review. Environ. Monit. Assess. 2015, 187, 201. [CrossRef] [PubMed]

20. Wang, S.L.; Xu, X.R.; Sun, Y.X.; Liu, J.L.; Li, H.B. Heavy metal pollution in coastal areas of South China: A review. Mar. Pollut. Bull. 2013, 76, 7-15. [CrossRef] [PubMed]

21. Gupta, S.K.; Singh, J. Evaluation of mollusc as sensitive indicator of heavy metal pollution in aquatic system: A review. IIOAB J. 2011, 2, 49-57.

22. Onozuka, H.; Amemiya, T.; Mizuishi, K.; Ono, Y. The concentration of trace elements in shellfish. Ann. Rep. Tokyo Metr. Res. Lab. PH 2002, 53, 253-257. (In Japanese)

23. Drescher, H.E.; Harms, U.; Huschenbeth, E. Organochlorines and heavy metals in the harbour seal Phoca vitulina from the German North Sea coast. Mar. Biol. 1977, 41, 99-106. [CrossRef]

24. Dallinger, R.; Berger, B.; Birkel, S. Terrestrial isopods: Useful biological indicators of urban metal pollution. Oecologia 1992, 89, 32-41. [CrossRef] [PubMed]

25. Hodkinson, I.D.; Jackson, J.K. Terrestrial and aquatic invertebrates as bioindicators for environmental monitoring, with particular reference to mountain ecosystems. Environ. Manag. 2005, 35, 649-666. [CrossRef]

26. Longo, G.; Trovato, M.; Mazzei, V.; Ferrante, M.; Conti, G.O. Ligia italica (Isopoda, Oniscidea) as bioindicator of mercury pollution of marine rocky coasts. PLoS ONE 2013, 8, e58548. [CrossRef]

27. Sun, J.; Liu, S.; Yan, Z.; An, S.; You, R.; Li, F.; Zhang, P. Influence of body weight and gender on the accumulation of heavy metals in Ligia cinerascens based on field investigation and Cd exposure experiment. Bull. Environ. Contam. Toxicol. 2019, 102, 811-816. [CrossRef]

28. Ohashi, N. Bioaccumulation of Dioxins in Fish and Shellfish from Tokyo Inner Bay. Ann. Rep. Tokyo Metr. Res. Lab. PH 2005, 56, 17-27. (In Japanese)

29. Pan, J.; Yang, Y.L.; Chen, D.Z.; Xu, Q.; Tang, H.; Li, Y.; Nie, L.M.; Jiang, K.; Xi, D.L. Distribution characteristics and source analysis of dioxins in sediments and mussels from Qingdao coastal sea. Chemosphere 2008, 70, 1699-1706. [CrossRef] 
30. Centers for Disease Control and Prevention (CDC). National Report on Human Exposure to Environmental Chemicals Updated Tables. January 2019. Available online: https:/ /www.cdc.gov/ exposurereport/index.html (accessed on 30 November 2020).

31. Domingo, J.L.; Bocio, A. Levels of PCDD/PCDFs and PCBs in edible marine species and human intake: A literature review. Environ. Int. 2007, 33, 397-405. [CrossRef] [PubMed]

32. Bruhn, R.; Kannan, N.; Petrick, G.; Schulz-Bull, D.E.; Duinker, J.C. Persistent chlorinated organic contaminants in harbour porpoises from the North Sea, the Baltic Sea and Arctic waters. Sci. Total Environ. 1999, 237, 351-361. [CrossRef]

33. Muir, D.; Braune, B.; DeMarch, B.; Norstrom, R.; Wagemann, R.; Lockhart, L.; Hargrave, B.; Bright, D.; Addison, R.; Payne, J.; et al. Spatial and temporal trends and effects of contaminants in the Canadian Arctic marine ecosystem: A review. Sci. Total Environ. 1999, 230, 83-144. [CrossRef]

34. Ito, K.; Uno, S.; Tanaka, H.; Miki, S.; Kokushi, E.; Yamamoto, M.; Koyama, J.; Añasco, N.C. Distribution of parent and alkylated PAHs in bivalves collected from Osaka bay, Japan. Jpn. J. Environ. Toxicol. 2015, 18, 11-24. [CrossRef]

35. Tanaka, H.; Onduka, T. Background levels of PAHs in the coastal waters of Japan based on residual concentrations of bivalves. J. Environ. Chem. 2010, 20, 137-148. [CrossRef]

36. Qiu, X.; Undap, S.L.; Honda, M.; Sekiguchi, T.; Suzuki, N.; Shimasaki, Y.; Ando, H.; Sato-Okoshi, W.; Wada, T.; Sunobe, T.; et al. Pollution of radiocesium and radiosilver in wharf roach (Ligia sp.) by the Fukushima Dai-ichi Nuclear Power Plant accident. J. Radioanal. Nucl. Chem. 2016, 311, 121-126. [CrossRef]

37. Undap, S.L.; Matsunaga, S.; Honda, M.; Sekiguchi, T.; Suzuki, N.; Khalil, F.; Qiu, X.; Shimasaki, Y.; Ando, H.; Sato-Okoshi, W.; et al. Accumulation of organotins in wharf roach (Ligia exotica Roux) and its ability to serve as a biomonitoring species for coastal pollution. Ecotoxicol. Environ. Saf. 2013, 96, 75-79. [CrossRef]

38. Tsai, M.; Dai, C. Life history plasticity and reproductive strategy enabling the invasion of Ligia exotica (Crustacea: Isopoda) from the littoral zone to an inland creek. Mar. Ecol. Prog. Ser. 2001, 210, 175-184. [CrossRef]

39. Hurtado, L.A.; Mateos, M.; Santamaria, C.A. Phylogeography of supralittoral rocky intertidal Ligia isopods in the Pacific region from Central California to Central Mexico. PLoS ONE 2010, 5, e11633. [CrossRef] [PubMed]

40. Kang, C.; Choy, E.J.; Son, Y.; Lee, J.; Kim, J.K.; Kim, Y.; Lee, K. Food web structure of a restored macroalgal bed in the eastern Korean peninsula determined by $\mathrm{C}$ and N stable isotope analyses. Mar. Biol. 2008, 153, 1181-1198. [CrossRef]

41. Aizawa, S.; Tsunoda, K.I.; Akatsuka, M.; Inoue, S.; Akaiwam, H. Evaluation of Trichoptera as an indicator organism for environmental pollution by heavy metals. Bunseki Kagaku (Jpn. Analyst) 1994, 43, 865-871. (In Japanese) [CrossRef]

42. Honda, K.; Yamamoto, Y.; Tatsukawa, R. Distribution of heavy metals in Antarctic marine ecosystem. Polar Biol. 1987, 1, $184-197$.

43. Di Leo, A.; Annicchiarico, C.; Cardellicchio, N.; Giandomenico, S.; Conversano, M.; Castellano, G.; Basile, F.; Martinelli, W.; Scortichini, G.; Spada, L. Monitoring of PCDD/Fs and dioxin-like PCBs and seasonal variations in mussels from the Mar Grande and the Mar Piccolo of Taranto (Ionian Sea, Southern Italy). Environ. Sci. Pollut. Res. 2014, 21, 13196-13207. [CrossRef]

44. Loganathan, B.G.; Kumar, K.S.; Masunaga, S.; Sajwan, K.S. Polychlorinated dibenzo-p-dioxins, dibenzofurans, and dioxin-like polychlorinated biphenyls in sediment and mussel samples from Kentucky Lake, USA. Arch. Environ. Contam. Toxicol. 2008, 54, 20-30. [CrossRef]

45. Fisher, N.S.; Stupakoff, I.; Sañudo-Wilhelmy, S.; Wang, W.X.; Teyssié, J.L.; Fowler, S.W.; Crusius, J. Trace metals in marine copepods: A field test of a bioaccumulation model coupled to laboratory uptake kinetics data. Mar. Ecol. Prog. Ser. 2000, 194, 211-218. [CrossRef]

46. Prato, E.; Biandolino, F.; Scardicchio, C. Test for acute toxicity of copper, cadmium, and mercury in five marine species. Turk. Zool. Derg. 2006, 30, 285-290.

47. Hong, J.S.; Reish, D.J. Acute toxicity of cadmium to eight species of marine amphipod and isopod crustaceans from Southern California. Bull. Environ. Contam. Toxicol. 1987, 39, 884-888. [CrossRef]

48. Kouba, A.; Buřič, M.; Kozák, P. Bioaccumulation and effects of heavy metals in crayfish: A review. Water Air Soil Pollut. 2010, 211, 5-16. [CrossRef]

49. Reish, D.J. Effects of metals and organic compounds on survival and bioaccumulation in two species of marine gammaridean amphipod, together with a summary of toxicological research on this group. J. Nat. Hist. 1993, 27, 781-794. [CrossRef]

50. Van Hattum, B.; Van Straalen, N.M.; Govers, H.A.J. Trace metals in populations of freshwater isopods: Influence of biotic and abiotic variables. Arch. Environ. Contam. Toxicol. 1996, 31, 303-318. [CrossRef] [PubMed]

51. Duquesne, S.; Riddle, M.; Schulz, R.; Liess, M. Effects of contaminants in the Antarctic environment-potential of the gammarid amphipod crustacean Paramorea walkeri as a biological indicator for Antarctic ecosystems based on toxicity and bioaccumulation of copper and cadmium. Aqua Toxicol. 2000, 49, 131-143. [CrossRef]

52. Munschy, C.; Guiot, N.; Héas-Moisan, K.; Tixier, C.; Tronczyński, J. Polychlorinated dibenzo- $p$-dioxins and dibenzofurans (PCDD/Fs) in marine mussels from French coasts: Levels, patterns and temporal trends from 1981 to 2005. Chemosphere 2008, 73, 945-953. [CrossRef] [PubMed]

53. Okumura, Y.; Yamashita, Y.; Kohno, Y. Bioaccumulation of PCDD/Fs and Co-PCBs in lower-trophic-level organisms in Sendai Bay, Japan. Water Air Soil Pollut. 2004, 159, 291-312. [CrossRef]

54. Bodin, N.; Abarnou, A.; Fraisse, D.; Defour, S.; Loizeau, V.; Le Guellec, A.M.; Philippon, X. PCB, PCDD/F and PBDE levels and profiles in crustaceans from the coastal waters of Brittany and Normandy (France). Mar. Pollut. Bull. 2007, 54, 657-668. [CrossRef] [PubMed] 
55. Han, Y.; Liu, W.; Zhu, W.; Rao, K.; Xiao, K.; Gao, L.; Su, G.; Liu, G. Sources of polychlorinated dibenzo-p-dioxins and dibenzofurans, and biphenyls in Chinese mitten crabs. Chemosphere 2018, 196, 522-530. [CrossRef]

56. Micheletti, C.; Critto, A.; Marcomini, A. Assessment of ecological risk from bioaccumulation of PCDD/Fs and dioxin-like PCBs in a coastal lagoon. Environ. Int. 2007, 33, 45-55. [CrossRef]

57. Okada, N.; Ye, T.; Kajitani, Y.; Shi, P.; Tatano, H. The 2011 Eastern Japan Great Earthquake Disaster: Overview and comments. Int. J. Disast. Risk Sci. 2011, 2, 34-42. [CrossRef]

58. Onozato, M.; Nishigaki, A.; Okoshi, K. Polycyclic aromatic hydrocarbons in sediments and bivalves on the pacific coast of Japan: Influence of tsunami and fire. PLoS ONE 2016, 11, e0156447. [CrossRef] [PubMed]

59. Shibata, T.; Solo-Gabriele, H.; Hata, T. Disaster waste characteristics and radiation distribution as a result of the Great East Japan Earthquake. Environ. Sci. Technol. 2012, 46, 3618-3624. [CrossRef]

60. Okumura, Y.; Kaneko, K.; Ota, H.; Nagasaka, H.; Hara, M. Analysis of environmental and microbiological changes in Onagawa Bay immediately after the tsunami of the Great East Japan Earthquake based on sediment cores. Mar. Pollut. Bull. 2020, 157, 111235. [CrossRef]

61. Ishiyama, M.; Matsuo, Y.; Nakai, K.; Tatsuta, N.; Nakata, H.; Mizukawa, H.; Miyawaki, T.; Nagasaka, H.; Someya, T.; Ueno, D. Temporal trends in PCB concentrations in mussels collected from areas affected by the Great East Japan Earthquake and Tsunami. Mar. Pollut. Bull. 2019, 145, 81-87. [CrossRef]

62. Ministry of the Environment, Japan (MOE). Press Release September 6th 2011. Available online: http:/ /www.env.go.jp/press/ press.php?serial=14180 (accessed on 28 November 2020). 